5. Vereckei A, Blazovics A, Gyorgy I, Feher E, Toth M, Szenas G, Zsinka A, Foldiak G, Feher J. The role of free radicals in the pathogenesis of amiodarone toxicity. J Cardiovasc Electrophysiol 1993;4:161-77.

6. Dootson G, Byatt C. Amiodarone induced vasculitis and a review of the cutaneous side effects of amiodarone. Clin Exp Dermatol 1994;19:422-4.

7. Duane PG, Rice KL, Charboneau DE, Niewoehner DE. Amiodarone induced endothelial injury is associated with phospholipase C mediated hydrolysis of membrane phospholipids. J Lab Clin Med 1992;120:955-63.

8. Holt DW, Tucker GT, Jackson PR, Storey GC. Amiodarone pharmacokinetics. Am Heart J 1983;106:840-7.

9. Shukla R, Jowett NI, Thompson DR, Pohl JEF. Side effects of amiodarone therapy. Postgrad Med J 1994;70:492-8.

10. Arnaud A, Neau JP, Rivasseau-Jonveaux T, Marechaud R, Gil R. Neurological toxicity of amiodarone: five case reports. Rev Med Intern 1992;13:419-22.

11. Honegger UE, Scuntaro I, Wiesmann UN. Vitamin E reduces accumulation of amiodarone and desethylamiodarone and inhibits phosholipidosis in cultured human cells. Biochem Pharmacol 1995;49:1741-5.

12. Feiner LA, Younge BR, Kazmier JF, et al. Optic neuropathy and amiodarone therapy. Mayo Clin Proc 1987;62:702-17.

P. Palimar

N. Cota

Department of Ophthalmic Surgery

Warrington Hospital

Kendrick Wing

Lovely Lane

Warrington

Cheshire WA5 1QG

UK

Sir,

\section{Reversible anterior ischaemic optic neuropathy in} accelerated hypertension

Anterior ischaemic optic neuropathy secondary to previously undiagnosed accelerated hypertension can present to the ophthalmologist. We report such a case in which the anterior ischaemic optic neuropathy reversed following prompt treatment of the hypertension.

\section{Case report}

A 41-year-old man presented to casualty with a $2 \mathrm{~h}$ history of reduced vision in the right eye. There were no associated symptoms and no past medical history of note. There was a history of moderate alcohol consumption and a cigarette smoking habit of 30 per day.

Examination revealed a right visual acuity of hand movements, a right relative afferent pupillary defect and the presence of right optic disc oedema. The left visual acuity was $6 / 6$ and fundoscopy revealed a cotton wool spot with a nerve fibre layer haemorrhage (Fig. 1). There was marked bilateral arteriolar narrowing. The blood pressure was recorded at 220/150 $\mathrm{mmHg}$ and the advice of a physician was sought for further investigation and management.

Following treatment with sublingual nifedipine $10 \mathrm{mg}$ the blood pressure fell to $160 / 110 \mathrm{mmHg}$. The following morning the right visual acuity had improved to $6 / 9$.
Full blood count, mean cell volume, urea and electrolytes, erythrocyte sedimentation rate, vitamin $B_{12}$, folate, urinary catecholamines and renal ultrasound were all within normal limits. Renal artery stenosis was excluded on the basis of normal clinical examination, urea and electrolytes and ultrasound.

Electrocardiography and echocardiography revealed left ventricular hypertrophy. Fasting serum cholesterol, triglycerides and low density lipoproteins were in the 'at risk' range and treatment with dietary advice and atorvastatin $20 \mathrm{mg}$ once daily was commenced.

The blood pressure is currently controlled with atenolol $100 \mathrm{mg}$ and bendrofluazide $2.5 \mathrm{mg}$ once daily. Two months following presentation the right visual acuity was $6 / 6$. Visual field testing revealed a nonspecific pattern of field loss and retinal photography 5 months after initial presentation (Fig. 2) confirmed resolution of the fundal changes with pallor of the right optic disc. Unfortunately the patient continues to smoke 20 cigarettes a day and his alcohol consumption remains unchanged.

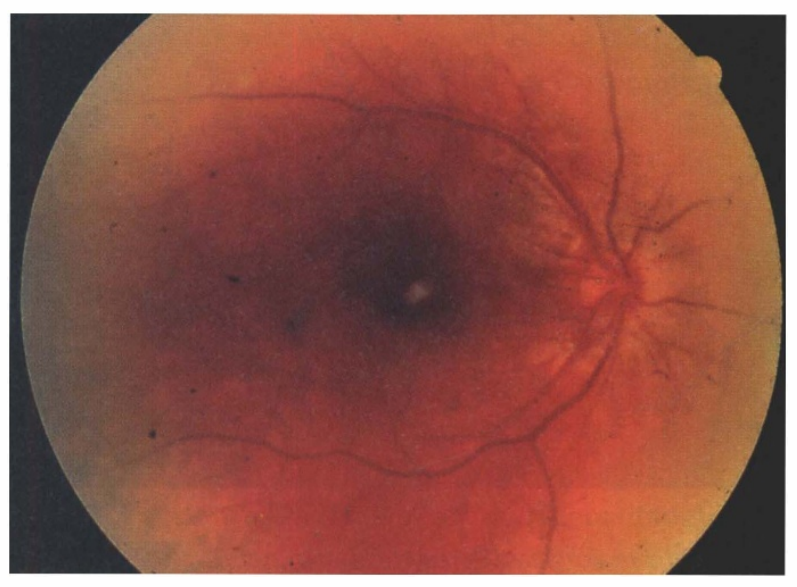

(a)

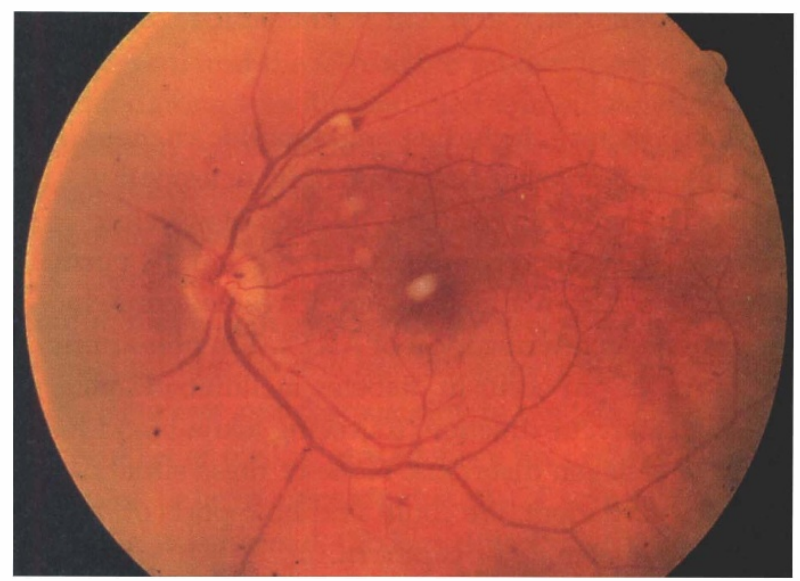

(b)

Fig. 1. At presentation. (a) The right optic disc is swollen and there is widespread arteriolar narrowing. Other 'abnormalities' are artefact. (b) A cotton wool spot, nerve fibre layer haemorrhage and arteriolar narrowing are visible in the left fundus. 


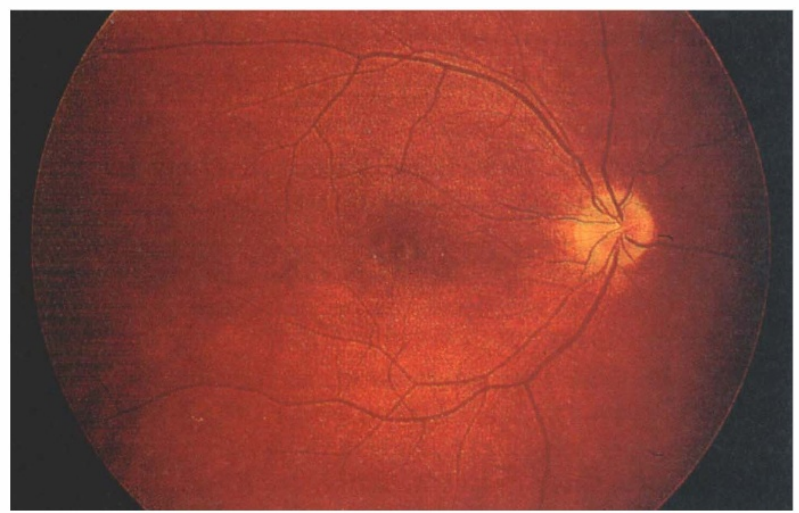

(a)

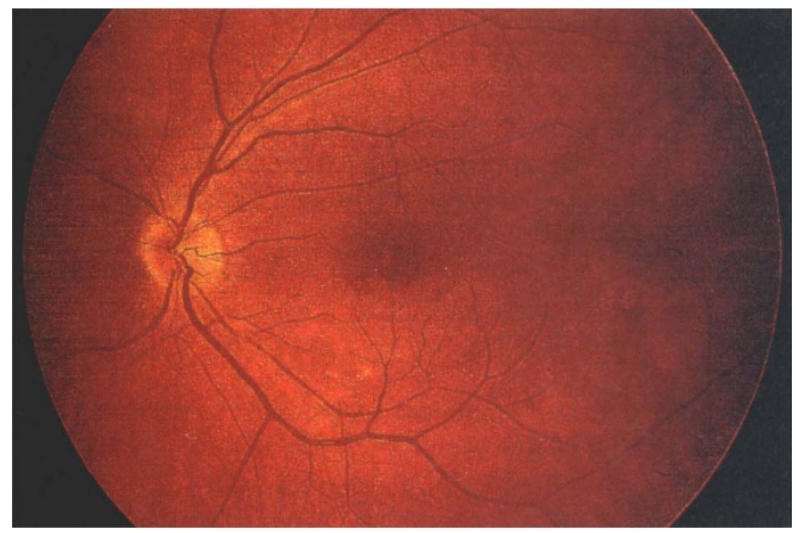

(b)

Fig. 2. Five months after presentation. (a) The right optic atrophy has developed and the arteriolar changes have reversed.

b) The haemorrhage, cotton wool spot and arteriolar narrowing have all reversed in the left fundus.

\section{Comment}

Accelerated hypertension can cause a retinopathy, choroidopathy and optic disc swelling. Clinical presentation is variable, reflecting the severity and speed of onset of the hypertension as well as the presence of pre-existing vascular disase. Accelerated hypertension produces changes in the autoregulation of the retinal and optic nerve head circulation. Autoregulation maintains a relatively constant blood flow during changes in perfusion pressure. The retina and optic nerve head autoregulate their circulation while the choroidal vascular bed does not. ${ }^{1}$

Optic nerve head ischaemia is produced by a combination of two factors: (i) involvement of the peripapillary choroid by vasoconstriction and vasoocclusive changes, and (ii) diffusion of angiotensin II and other endogenous vasoconstrictors into the optic nerve head from the peripapillary choroid. Disc oedema is thought to occur due to ischaemia interfering with axoplasmic flow in the optic nerve head. ${ }^{2}$

Hayreh's studies $^{3}$ on experimental renovascular accelerated hypertension in rhesus monkeys showed that hypertensive optic neuropathy is a distinct entity, that it is not simply a part of hypertensive retinopathy and that it represents one form of anterior ischaemic optic neuropathy. Talks et al. ${ }^{4}$ suggested that during the acute stage of accelerated hypertension the ischaemic optic neuropathy may be reversible. Reversibility is clearly demonstrated by this case.

The regulatory mechanisms controlling optic nerve circulation are not fully understood. Factors affecting the reversibility of anterior ischaemic optic neuropathy in this patient may include age, lack of coexisting disease, early presentation and immediate treatment. The absence of any previous history of hypertension in this patient emphasises the importance of checking the blood pressure in all patients with anterior ischaemic optic neuropathy. Precipitous reduction of the blood pressure in patients with hypertensive optic neuropathy may cause complete permanent blindess. ${ }^{5}$

\section{References}

1. Hayreh SS. Systemic arterial blood pressure and the eye. Eye 1996;10:5-28.

2. McLeod D, Marshall J, Kohner EM. Role of axoplasmic transport in the pathophysiology of ischaemic disc swelling. Br J Ophthalmol 1980;64:247-61.

3. Hayreh SS, Servais GE, Virdi PS. Fundus lesions in malignant hypertension. V. Hypertensive optic neuropathy. Ophthalmology 1986;93:74-87.

4. Talks SJ, et al. The acute and long-term ocular effects of accelerated hypertension: a clinical and electrophysiological study. Eye 1996;10:321-7.

5. Taylor D, Ramsay J, Day S, Dillon M. Infarction of the optic nerve head in children with accelerated hypertension. $\mathrm{Br} \mathrm{J}$ Ophthalmol 1981;65:153-60.

\author{
M.J. Gallagher \\ R.S. Haslett \\ R.P. Phillips \\ Arrowe Park Hospital \\ Wirral, UK
}

R.S. Haslett, BM, MRCP, FRCOphth

Arrowe Park Hospital

Arrowe Park Road

Upton

Wirral

Merseyside L49 5PE, UK

Tel: $+44(0) 1516785711$

Fax: +44 (0)151604 7152

Sir,

External ocular myiasis due to Oestrus ovis in a tourist returning from North Africa

The sheep nasal botfly Oestrus ovis is the commonest of several species of dipteran fly whose larvae are obligatory parasites in the nasal cavities and frontal sinuses of sheep but may cause infestation (myiasis) in man. Ocular myiasis is rarely reported in the UK. We report a case of imported external ocular myiasis due to O. ovis presenting in London. 